\title{
Opportunities for Financing Bulgarian Cultural Organizations (Chitalishta)
}

\author{
Ch. Assist. Prof. PhD Silviya Dimitrova \\ University of Economics - Varna, Varna, Bulgaria \\ silvia_dimitrova@ue-varna.bg \\ Svetoslav Stoychev \\ titi_sv@abv.bg
}

\begin{abstract}
Cultural resources are enormous, they are renewable and they must be considered as significant social and economic development drivers. In recent years, their contribution to a higher quality of life has been recognized at various levels. This is not the case with their financing. Financial solutions are still far from affordable and accessable. In this regard, the article examines the possibilities for financing the typical Bulgarian cultural institutions, namely the Chitalishte. First, the ways and methods of financing existing in the EU and in the world are presented. After that, the real possibilities for them are evaluated in the Bulgarian context.
\end{abstract}

Keywords: financing, chitalishta, cultural organizations, options

JEL Code: Z18, Z19; doi:10.36997/IJUSV-ESS/2019.8.3.128

\section{Въведение}

Културата играе важна роля в подобряването на привлекателността и подчертаването на уникалната идентичност на определени места. Проблемът с финансирането на културата и в частност на читалищата е ключов за страните от ЕС. В изслушването си пред комисиите в Европейския Парламент за мандат като еврокомисар Мария Габриел подчерта жизнената необходимост за увеличаване бюджета за култура. Тя посочи, че съвместната политика и финансирането на културата наистина са от съществено значение, тъй като културата обхваща много области на политиката - от образование до научни изследвания, от социално сближаване до външни отношения. Съществува значително финансиране от ЕС за култура в други програми. Например, през периода 2014-2020 г. общото финансиране за култура от европейските структурни и инвестиционни фондове може да бъде оценено на над 9 милиарда евро, много повече от финансовите възможности на програмата „Творческа Европа““.

Като част от културните институции, читалищата имат важна роля в насърчаването на социалното включване. Те подкрепят основните принципи на културната политика представяне на културната идентичност, творчеството, културно многообразие, подкрепа участието на населението в културни дейности, в контекста на придържане към свобода на изразяването, културните права и развитието на демократично гражданско общество (Council of Europe, 1997). Още поддържат и работят за постигането на устойчивите цели на хилядолетието (SDG)- спазване на правата на човека, образование, развитие на личността; мобилност на творци; включване на културата в устойчивото развитие, постигане на балансиран поток от културни стоки и услуги и увеличаване мобилността на културните професионалисти (UNESCO, 2018).

Предизвикателствата пред финансирането в последните години бяха свързани с преодоляването на намалените бюджети и намалените културни разходи в резултат на глобалната криза. Традиционно подкрепян сектор в европейските икономики и политики, културата отново е на дневен ред. Анализите показват, че повечето държави-членки на ЕС полагат значителни усилия за финансиране на културния сектор, но последиците от икономическата криза оказаха отрицателно въздействие върху това финансиране. От тази гледна точка те породиха пропаст между северните и централни държави от ЕС, от една страна, и държавите в южната и източната част на Съюза, от друга страна и очертаха 
културна Европа с две периферии (С̌opič et al., 2013). Широко признати приоритети за страните-членки на ЕС, в това число и за България са:

- Културното образование, или по-широко културата за деца и млади хора, е запазило стратегическа позиция в националните разходи. Установеният, институционализиран характер на библиотеките може да обясни финансовата стабилност на този сектор, съчетан с успешно преминаване към цифрови информационни устройства и с предлагане на много обществени услуги.

- Фокусът върху необходимостта от обслужване на местните общности обяснява защо на ниво общини в държавите-членки на Съюза от Източна Европа, финансирането за местни културни центрове, поддържа традиционно силна позиция.

- Лекото абсолютно и относително намаление на разходите за опазване на наследството могат да бъдат свързани с общото намаляване на всички капиталовложения.

Възстановяването в някои сфери и за някои страни е по-бавно (заради периферията и центъра). От друга страна, новите технологии привличат вниманието на населението към друг тип занимания и развлекателните индустрии заемат значително място в свободното време на хората. Средствата от държавните и общински бюджети не са достатъчно и това налага необходимостта да се търсят алтернативни източници за тяхното финансиране. България е една от тези страни, където все още съществуват редица пречки и недоизползвани възможности за финансиране на културата и в частност културните институции. В тази връзка статията разглежда възможните алтернативи за финансиране на българските читалища.

\section{1. Тенденции във финансирането на културата}

Основните модели за финансиране на културата са 3 и обикновено се формулиран като държавно подкрепян, пазарнообусловен и смесен модел. Характеристиките на всеки един от тях са в зависимост от това по какъв начин са решени взаимните и сложни връзки между правителството, частния сектор и третия сектор, се формират също различни модели на културна политика. Те представят отношенията между произвеждащите култура, потребяващите я и тези, които регулират процесите в тази сфера.

Публичното (държавно) финансиране се осъществява основно в три области - една, свързана с неговия пряк принос (субсидиите), относно поддържането на високо ниво на местните инвестиции (средствата на местно ниво) и на трето място, да се увери за найдоброто възможно изразходване на средства, които не контролира пряко, тоест частния сектор. Този модел е свързана с обусловеността на културата като публично благо и наличните пазарни дефекти. Както Mundy изтьква, в сферата на културата, правителството избира до каква степен и по какъв начин да се намеси на пазара, за да направи налична желана работа, която не е непременно популярна или самоиздържаща се (Mundy, 2000).

Пазарнообусловеният модел е свързан с либералната идея, че парите най-добре се използват в частния сектор. Икономиката на свободния пазар е най-ефективната система за стимулиране на естетическа продукция, осигуряване на творческа свобода и усъвършенстване на културното многообразие (Mulcahy, 1995).

Смесените модели се формират поради участието едновременно на елементи от предните два (държавата и частния сектор във финансирането). Най-често съществуват различни съвети и комитети по култура, като са характерни два принципа за подкрепа в общия случай. Основните принципи на разпределение на средствата са принципа „на една ръка" (arm's length) (Throsby, 2001). При него решенията се вземат от независими органи, обикновено наричани Съвети по изкуства (по името на този създаден в Великобритания през 40-те на XX век). Както Throsby предполага, задачата му е да гарантира, че решенията за 
финансиране ще са неподвластни на политическо влияние, тоест независими . Критиците обясняват, че прякото политическо вмешателство в работата на Съветите по изкуства е станало неизбежно в резултат на по-голямата отчетност, която се изисква от тях. При използването на експерти (,,peer's review principle”) подкрепата се определя от тези, които са запознати с изкуството и се предполага, че могат да преценят кой си заслужава да бъде подпомогнат (пак там).

В миналото много културни проекти и инвестиции се осигуряват чрез сравнително пряко финансиране, било то публично финансиране, частни интервенции или така нареченото финансиране от трета сфера (благотворителни организации, фондации, организации с нестопанска цел). В някои части на света силният обществен контрол, държавно регулиране, финансиране и културни политики са почти правило. В други частното финансиране е преобладаващо. Но все още има много държави, на които липсват както ефективна публична намеса, така и частни финансирани инициативи за културни проекти.

Важен момент, който трябва да се следи при частното финансиране е, че ще има помалко финансови ресурси за култура, ако няма признати икономическа стойност за проекта. Също така няма да има признати икономически ценности, ако културните въздействия не бъдат измерени системно и цялостно и не се споделят и разпространяват между всички заинтересовани страни (UNESCO, 2016). Ключовият фактор е дали инвестицията е финансово оправдана. Примерите, свързани с емблематични паметници в градовете със световно наследство, имат потенциал за рентабилност за привличане на инвеститори. По подобен начин проектите за съживяване на културни институции могат да облагодетелстват всички жители, включително и такива с високи доходи, бизнеса на дребно или едро. Всичко посочено произтича от икономическата и културна стойност на тези институции (Throsby, 2001, Throsby, 2011). Освен финансово изгодни, проектите за култура трябва да са и икономически обосновани, тоест да социалните и икономическите резултати от инвестицията да не генерират социални и икономически разходи, които не се вземат предвид от частните инвеститори. Натрупването на пътни задръствания, екологични и социални щети, социално изключване са някои примери за това. Съществува консенсус, че стабилната оценка на икономическата стойност трябва да бъде направена преди всяко частно или публично решение в областта на културата, както и че подкрепата за културата трябва да бъде поставена в основата на други области на икономическата и социалната политика (KEA European Affairs, 2012).

Различията между държавите по отношение на комбинацията от доминиращите финансови модели (публично финансиране, частни интервенции и т. нар. финансиране от третата сфера) за културата се влияе от местните условия като растеж, ниво на доходите, публично управление, фискална система и банкови структури, от териториалното устройство, държавната политика, централизация или децентрализация. Важно условие е финансовите механизми да бъдат адаптирани към местните условия. Последните процеси на децентрализация водят до промяна на организацията на културните дейности и институции като отговорната администрация по въпроса се реорганизира. В резултат се дава се поголяма отговорност на по-ниските нива и се очаква съответно по-активно участие и ангажираност от тях, тоест повече отговорност и мотивация.

Още преди десетилетия са посочени четири вида мерки от местните власти, които ще се превърнат в обща практика за всички страни в бъдеще (UNESCO, 2016).

Административните мерки имат за цел да създадат благоприятни условия за потенциалните инвеститори. Това включва предоставяне на полезна информация за използването или повторното използване на културното наследство, плановете за управление на единични паметници или зони с признато значение, опростяване на административните 
процедури, назначаване на координатори на проекти и оператори на терен и приемане на благоприятни политики за наем.

Мерките за намеса имат за цел да мобилизират частните инвеститори, да насьрчат инвестирането на печалби в нови дейности за опазване чрез револвиращи средства и подобряване на жилищата и програми.

Финансовите мерки включват предоставяне на субсидии (или помощи за безвъзмездни средства), интервенция по заема (ниски ипотечни проценти, публични гаранции, по-дълъг период на изплащане) и данъчно облагане в полза на инвестиционни и рискови инициативи (данък върху културния туризъм, данък върху доходите и печалбата, данък върху наследството, данъци върху земята и имотите, данък върху добавената стойност върху културните продажби).

Могат да бъдат предприети конкретни мерки за насърчаване на спонсорството за насърчаване на дарения или покровителство чрез данъчни стимули (за физически лица, компании, фондации и организации с нестопанска цел) и чрез подходящи законови рамки за насърчаване на филантропията и благотворителните организации в подкрепа на културни проекти. Днес има много специфични източници на финансиране, включително лотарии, концесионни споразумения, прехвърляне на права за развитие, инициативи за масово финансиране.

Освен традиционните инвестиции в култура, изцяло управлявани от публични средства (безвъзмездни средства, заеми или стимули), съществуват и други подходи, които смесват публичното и частното финансиране. Ако до този момент финансирането на културата обикновено се разглежда като процес „отгоре надолу”, сега нови заинтересовани страни заемат водеща роля, включително общности и собственици на имоти в градските райони. Следователно публично-частните партньорства следва да бъдат засилени. Ясно е, че предвид обществените добри характеристики на ценността на наследството, историческите градски ядра и недостатъчно използваните земи със статут на наследството, икономическата обосновка за инвестициите в публичния сектор е добре установена. Въпреки това е неразумно да се очаква публичният сектор да бъде единствен инвеститор. От друга страна, вероятно самият частен сектор ще осигури неоптимално преустройство и недостатъчно осигуряване на инвестиции поради наличието на рискове и външни фактори, понякога поради проблеми с координацията между частните агенти. Решението е да има комбинация от публични и частни инвестиции с баланс между двете, вариращи в зависимост от схемата на проекта и контекста.

В действителност местните условия определят как да се възползват културните институции от широкия спектър от надеждни финансови инструменти. Местните заинтересовани страни трябва да засилят инвестициите си в културни проекти, за да допринесат за създаването на работни места, стабилните доходи, благосъстоянието и подобряването на жизнеспособността на дадено място, като вземат предвид, че финансовата възвръщаемост от частни или публични инвестиции в градски културни проекти носи поголеми резултати. Местните власти имат решаваща роля за това подобряване на управлението и финансирането на културните ценности в техните градове. Нова тенденция е разпространението на инициативи в областта на т. нар. масово финансиране (crowdfunding).

Масовото финансиране се превърна в иновативен метод за сближаване на инвеститорите и тези, които изискват капитал, особено когато последните развиват артистични, културни, социални или други видове инициативи. То се разглежда като инструмент, който дава възможност за демократизиране на финансирането. Обикновено се активира чрез интернет посредством социални медии (Lehner, 2013) и позволява на предприемачите да достигат до географски разпръснати хора по целия свят, които са готови да подкрепят проекта (Saxton and Wang, 2014). Една от характеристиките на тези проекти е наличието на цел за финансиране (Mendes-Da-Silva et al., 2016). Този метод дава възможност 
за сравнително малки суми, предоставени от голям брой хора, да направят бизнеса жизнеспособен по по-гъвкав и по-евтин начин, който не изисква междинни финансисти. Краудфандингът е описан като натрупване на малки инвестиции в отделни проекти от голям брой хора, които са подкрепени от платформа (Royal and Windsor, 2014). В резултат на това явление се появяват много платформи за набиране на средства. Един пример е Kickstarter, която в момента е най-голямата платформа в света. Kickstarter е северноамерикански уебсайт, който хоства проекти, включващи филми, игри, музика, дизайн и технологии. От старта си през 2009 г. тя привлича повече от 1,5 милиарда долара от 5,1 милиона души, които финансират над 50000 творчески проекта (Qiu 2013). Въпреки че Световната банка и специализираните консултанти посочват бързия растеж на този начин на финансиране, той все още е силно концентриран в Северна Америка и Европа (съответно 59 и 35\% от общата стойност по света) с незначителен присъствие в развиващите се континенти.

Успешен пример за масово финансиране е и този в Базел. През 2012 г. отдельт за културни услуги в кантона Базел-Щад разработва регионален портал за краудфандинг в партньорство с швейцарска платформа, с цел насьрчаване на творческото производство, културното разпространение и участието. Инициативата се оказва изключително успешна в допълването на обществената подкрепа, по-специално за нишови проекти или други, които не отговарят на обичайните критерии за субсидии - например тромпет с две камбани и албум с експериментални звуци, наред с много други. Само за три години той успява да събере над 1 милион долара, което допринесе за видимостта и жизнеспособността на повече от 250 местни творчески проекта. (UNESCO, 2018).

Не на последно място, културните проекти в устойчив градски контекст могат да бъдат финансирани като част от по-широки програми от технологичен и икономически характер (например интелигентни градове), изграждане на мрежи, насърчаване на иновациите и креативността с акцент върху културните и творческите индустрии. Във времена на остра конкуренция между градовете за привличане на нови жители, посетители и бизнес, културните и природните ресурси се превърнаха в решаващи фактори за подпомагане на регионите да се развиват, подкрепяйки творческия талант, засилвайки устойчивия туризъм и насърчавайки социалното сближаване. Заедно с фискалните стимули, местните трудови умения и средства за комуникация се очаква градовете да притежават начин на живот, качество на живот, съвременен градски дизайн, културни услуги и, разбира се, природно и културно наследство. По-голямата част от тях са достъпни посредством фондовете на ЕС.

\section{2. Алтернативи за финансиране на читалищата в България}

Читалищата са типично българска обществена институции, които изпълняват учебнопросветителски функции и самодейност. Като институция винаги са били подкрепяни в страната в ролята си на изразители на националната идентичност, средство за социално сближаване и трибуна за творческа изява.

Обикновено се състоят от библиотека и клуб по интереси, където се развиват найразлични дейности от любителски школи по музика, танци, спорт, чужди езици, театър, литературни четения, отбелязване на обществено значими събития за града и празници, организиране на конференции и градски събрания. Някои читалища през 90-те години служат и за киносалони, пенсионерски или партийни клубове.

В съответствие със Закона за народните читалища (2013) те набират средства от следните източници:

- членски внос;

- културно-просветна и информационна дейност;

- субсидия от държавния и общинските бюджети;

- наеми от движимо и недвижимо имущество; 
- дарения и завещания;

- други приходи.

Основен източник за средства остава държавната субсидия, която се отпуска на читалищата чрез съответните общински бюджети. В това отношение като негативен момент може да се посочи прекалената обвързаност на читалищата с бюджета. Отменянето на чл. 7 от ЗНЧ (2013), който предвижда създаването на фонд “Читалища и читалищно дело" към Министерството на културата на практика стопира една възможност за набиране на средства и пряко подпомагане на читалищата при реализиране на техни културни проекти и програми. Това се отразява и на въздействието на държавата за осъществяване на културната си политика в онези селища, където читалищата са единствените граждански и културни институции

Дьржавната субсидия за читалищата се определя всяка година с приемането на държавния бюджет. Понастоящем читалищата са в системата на т.нар. делегирани от държавата дейности. Средствата от държавния бюджет се определят на базата на субсидирана численост, като една субсидирана бройка е обвързана със стандарт, в който са разчетени средства, за заплата, осигуровки и веществена издръжка. Предложенията за годишната субсидия за читалищата по общини, нормативите и механизмът за нейното разпределяне се разработват от Министерството на културата, съгласувано с областните администрации и общините.

Таблица 1. Дьржавна субсидия за читалищата за периода 2015-2019 година (в лева)

\begin{tabular}{|l|c|c|c|c|c|}
\hline \multicolumn{1}{|c|}{ Година } & $\mathbf{2 0 0 8}$ & $\mathbf{2 0 1 6}$ & $\mathbf{2 0 1 7}$ & $\mathbf{2 0 1 8}$ & $\mathbf{2 0 1 9}$ \\
\hline $\begin{array}{l}\text { Стандарт за една субсидирана } \\
\text { бройка }\end{array}$ & 5829 & 7080 & 7300 & 8357 & 9490 \\
\hline $\begin{array}{l}\text { Субсидирани бройки през } \\
\text { съответната година }\end{array}$ & 6575 & 7479 & 7559 & 7559 & 7644 \\
\hline
\end{tabular}

Общият бюджет за култура през 2019 година е близо 194,4 млн. лева като увеличението е с над 19 млн. лв. (2018). В посочената сума обаче влиза приетото увеличение от $10 \%$ на заплатите, което включва читалищата, общинските и регионални музеи и художествени галерии, както и $20 \%$ увеличение на средствата за училищата по изкуства. За читалищата сумарното увеличение е над $13 \%$, което включва увеличението на заплатите. Отчитайки проблемът с остарялата материална база, нуждаеща се от ремонт, както и необходимостта от модернизиране, автоматизация, а не на последно място и попълване на библиотечния фонд с традиционни и съвременни носители на информация. Тези средства не са достатъчни, за да покрият широкия спектър на дейностите за запазване и развиване на художествената дейност, особено в по-малките населени места. В държавния бюджет са отпуснати и допълнително средства в размер на 9352000 лв., които също бележат растеж, но само в номинално изражение. Представеното голямо разнообразие на дейностите, осъществявани в тези институции, не се отразява съразмерно в бюджета, отделян за читалищата от държавата. Въпреки обявеното увеличение в бюджетите за тях, за дейности трудно остават средства. Дори и за нещо толкова значимо и пазещо идентичността като необходимостта от финансиране на пътните разходи на учениците.

С решение на общинския съвет читалищата могат да се финансират допълнително над определената по ал. 1 субсидия със средства от собствените приходи на общината. Така гласуваната от общинския съвет субсидия за народните читалища не може да се отклонява от общината за други цели. Предвидените по държавния и общинския бюджет средства за читалищна дейност се разпределят между читалищата от комисия с участието на представител на съответната община, на всяко читалище от общината и се предоставят на читалищата за самостоятелно управление. При недостиг на средства за ремонта и 
поддръжката на читалищна сграда средствата се осигуряват от общинския съвет.

Процедурата за финансиране след това включва:

- представяне на отчета за изразходваните от бюджета средства в общината, на чиято територия се намира читалището,

- председателите на народните читалища на територията на съответната община ежегодно в срок до 10 ноември представят на кмета насоките за дейност през следващата година.

- кметьт на общината внася направените предложения в общинския съвет, който приема годишна програма за развитие на читалищната дейност в съответната община,

- програмата се изпълнява от читалищата въз основа на финансово обезпечени договори, сключени с кмета на общината,

- председателят на читалището представя ежегодно до 31 март пред кмета на общината и общинския съвет доклад за осъществените читалищни дейности в изпълнение на програмата и за изразходваните от бюджета средства през предходната година,

- докладите на читалищата на територията на една община се обсъждат от общинския съвет на първото открито заседание след 31 март с участието на представителите на народните читалища - вносители на докладите.

На следващо място, законът предоставя и възможности за финансиране дейността на читалищата от отдаването под наем на площи, но те не могат да отчуждават недвижими вещи и да учредяват ипотека върху тях. Движимите вещи, от своя страна, могат да бъдат отчуждавани залагани, бракувани или заменени с по-доброкачествени само по решение на настоятелството.

Видно е, че търсенето на алтернативи се явява предизвикателство за секретарите и председателите им.

Към момента активна и достьпна за читалищата за кандидатстване по Национален Фонд "Култура" е Програма "Мобилност", Модул „Професионални културни организации и артисти“ (НФК, 2019). Програмата е за финансиране на транспортни разходи на български артисти и представители на културата и изкуствата за участия в международни, национални и локални културни форуми или посещения на чуждестранни артисти и представители на култура и изкуства. Обявеният конкурс е за финансиране на: участия в международни, национални и локални културни форуми на непрофесионални представители на българската култура и изкуство. Финансираните проекти могат да са свързани с: проекти, предвиждащи участието на български творци на международни, национални и локални културни форуми (културни събития, програми, фестивали, дебати, конференции, семинари и др.); проекти, предвиждащи посещения на чуждестранни артисти, мениджъри и програматори в областта на културата и изкуствата на национални и локални културни форуми; проекти за включването на български творци в международен културен обмен, международни културни мрежи и инициативи и проекти за децентрализация на културните прояви.

Също така, един от основните работещи механизми в страната е по Финансовият механизъм на Европейското икономическо пространство 2014-2021 г., който предоставя средства, осигурени от Кралство Норвегия, Република Исландия и Княжество Лихтенщайн. Целта е намаляване на икономическите и социалните различия в Европа и засилване на двустранните отношения между страните-донори и страните-бенефициенти чрез финансиране на няколко приоритетни сектора, сред които култура, гражданско общество, добро управление, основни права и свободи (EEGrants, 2019).

Реални алтернативи сьществуват и по Програма „Културно предприемачество, наследство и сътрудничество“, на която Министерството на културата е в качеството си на Програмен оператор, към която е отворена покана за подаване на проектни предложения по 
Резултат 2 „Подобрен достьп до изкуства и култура“. Целта на подкрепата на такива проекти е укрепване на капацитета на културните оператори и повишаване качеството на живот на общностите. Програма РА14 „Културно предприемачество, наследство и сьтрудничество“ се фокусира върху ролята на културата и културното наследство като ресурси за местно и регионално развитие. В този смисъл Резултат 2 „Подобрен достъп до култура и изкуства“ (размер на $3164706 €$ ) ще подкрепи проекти, позволяващи организирането на разнообразни артистични и творчески събития, фестивали, изложби и инициативи, които ще съживят периферните пространства, ще вдъхнат нов живот в по-малки градове и села и не на последно място - ще привлекат и ангажират нови публики. В същото време Министерство на културата обяви и втора конкурсна сесия по Програма „Българските библиотеки съвременни центрове за четене и информираност“ за 2019 г. (Министерство на културата, 2019 б).

Обхватът на дейностите, извършвани в читалищата, в известна степен ограничава възможностите на този етап от гледна точка изпълнението на условията за кандидатстване като бенефициент по Програма Медиа например и други, предоставяни от ЕС.

Необходимостта от технологична подкрепа за НПО, читалища и обществени библиотеки и тяхната важна за обществото работа е осъзната от TechSoup България. Програмата е ориентирана изцяло към неправителствените организации и нуждите им, като ги снабдява с лицензирани софтуерни продукти, чиято пазарна стойност е почти 420000 лв. TechSoup България стартира у нас през 2009 г. в резултат на партньорството между базираната в Сан Франциско организация TechSoup Global и Фондация „Работилница за граждански инициативи" (ФРГИ) (Фондация „Работилница за граждански инициативи").

Специфичността на дейностите на читалищата (съвместяването на библиотеки, концертни зали, места за социално включване на малцинства, място за себеизява и професионално развитие) ги поставят в положението на възможен бенефициент по програма Give Eur-Норе. Тя е основана през 2010 г. от асоциацията на европейските институции и подпомага инициативи в социокултурната сфера с идеята да се развива споделянето на знание, включително и чрез творческа изява (Give Eur-Hope, 2010).

Ако разгледаме на макроравнище, възможностите за финансиране на българската култура също не са много. В стратегията за развитие на българската култура за периода 2019-2029 дельт на средствата за култура намалява от половин процент на 0.4 процента още от 2020 г. при необходим възприет минимум за устойчива и работеща политика от 2\% (Министерски съвет, 2019а). През 2009 г. се е доближавал повече, отколкото в настоящия момент - в размер на 1,72\% (Council of Europe, 2011).

Според експерти в сферата прави впечатление липсата на каквито и да било алтернативни източници, познати от страните - членки на ЕС. В Закона за развитие и закрила на културата частните неправителствени организации са равнопоставени на държавните и общинските. Но подобен инструментариум не е разработен в националната стратегия. (Димитров, 2019). В проекта се споменава Законът за меценатството във връзка с дарителство и спонсорство за културата. В него е заложено създаването на арт лотария инструмент, познат в рамките на ЕС, който служи като втори стълб за финансирането на културните дейности. В действителност обаче този закон не предлага практически механизми, които да насьрчават меценатството. Отговорност има и от страна на Министерство на финансите, което да определи докъде може да се стигне с данъчните преференции по отношение на спонсори, дарители и меценати.

Като алтернативен източник Национален Фонд Култура е създаден през 1999 г. с приемането на Закона за закрила и развитие на културата (1999). Започва да действа през ноември 2000 г. като основната му цел е да подпомага развитието на културата в съответствие с националните културни политики, заложени в държавните програми за съответния период и посочени в Закона за защита и развитие на културата. Идеята при 
създаването му е да служи като организация, която е на една ръка разстояние. Както посочихме по-горе, основната цел при тях е върху културните дейности да няма пряк политически контрол. В действителност обаче, към настоящия момент, фондът представлява само административна програма. Причината е, че той е под отговорността на Министерството на културата и не може да изпълнява заложените му цели. Друга посочена възможност са отчисленията от хазарта към Национален фонд "Култура". За разлика от Унгария в България те не се събират, въпреки че са определени в Закона за хазарта (2017) със специален член, който гласи, че $10 \%$ от приходите от онлайн и офлайн такси, които се събират, ще се отчисляват към НФК.

Тази стратегия, както е предложена по проект, не предлага работещи алтернативи за културата и читалищата. Причините се дължат на факта, че тя не е свързана и с икономическото развитие на страната и не на последно място, тя е сведена до документ на Министерството на културата и в нея няма връзки с останалите отговорни министерства и институции.

\section{Заключение}

В България липсва цялостна система от алтернативни източници за допълнителна субсидия за различните изкуства, за културното наследство и за читалищата. Осигуряването на такива, в това число български и чужди, за финансиране на културни проекти се постига благодарение на децентрализацията. За да работи успешно този принцип е необходимо едновременно с него да се увеличава самостоятелността на културните субекти, да се намират подходящи действащи модели на автономност, съобразени с тяхната специфика, активизиране и поддържане на постоянен диалог с местната власт за ефективно разпределение на държавните и национални ресурси за подпомагане на културата, както и осигуряване на реална равнопоставеност на културните субекти при новите условия и категорично налагане на конкурсното начало за получаване на подкрепа от държавната субсидия; създаване на целеви фондове по различни национални културни програми.

\section{References}

1. Council of Europe. (1997) In from the margins: A contribution to the debate on culture and development in Europe. Strasbourg:Council of Europe Publishing.

2. Council of Europe. (2011) Compendium on cultural policies and trends. Available from: http://www.culturalpolicies.net/web/countries-quick-facts.php?pcid=1090 23.10.2019].

3. Čopič, V., Inkei, P., Kangas, A. and Srakar, A.(2013) Trends in Public Funding for Culture in the EU. EENC Report.

4. Dimitrov, Iv. (2019) "Diana Andreeva, finansist: Strategiyata za kultura prilicha na uprazhnenie na student", Dnevnik, 19 mart, Available at: https://www.dnevnik.bg/intervju/ 2019/03/19/3406007_diana_andreeva_finansist_strategiiata_za_kultura/ 20.10.2019].

5. EEGrants. (2019) Available from: https://www.eeagrants.bg/programi/kultura/novini/nad-250organizaczii-se-vklyuchixa-v-informaczionnata-kampaniya-na-programa-

$\%$ E2\%80\%9Ekulturno-predpriemachestvo,-nasledstvo-i-strudnichestvo

[Accessed 20.10.2019].

6. Fondatsiya „Rabotilnitsa za grazhdanski initsiativi". (2009) Available from: https://www.techsoup.bg/node/15291 [Accessed 20.10.2019].

7. Give -Eurhope. Available from: http://www.giveeurhope.eu/en/) [Accessed 20.10.2019].

8. KEA European Affairs. (2012) Use of structural funds for cultural projects, Brussels, Available from: https://keanet.eu/wp-content/uploads/2019/09/structuralfundsstudy.pdf [Accessed 15.05.2014]. 
9. Lehner, O. M. (2013). Crowdfunding social ventures: A model and research agenda. Venture Capital: An International Journal of Entrepreneurial Finance, 15(4), pp.289-311.

10. Mendes-Da-Silva, W., Rossoni, L., Conte, B. S., Gattaz, C. C. and Francisco, Ed. R. (2016) The impacts of fundraising periods and geographic distance on financing music production via crowdfunding in Brazil. Journal of Cultural Economics. 40, pp.75-99.

11. Ministerstvo na finansite. (2017) Zakon za hazarta. DV, br. 103 от 28.12.2017 г. Available from: http://www.dkh.minfin.bg/bg/page/10 [Accessed 10.01.2018].

12. Ministerstvo na finansite. (2018) Byudzhet na Republika Balgariya. Available at: https://www.minfin.bg/bg/1234 [Accessed 20.09.2019].

13. Ministerstvo na kulturata. (1999) Zakon za zakrila i razvitie na kulturata.DV, br. 50 от 1.06. 1999г.

14. Ministerstvo na kulturata. (2013) Zakon za narodnite chitalishta. DV, br. 68 от 2.08.2013.

15. Ministerstvo na kulturata. (2019a) Proekt za strategiya za balgarskata kultura. Available from: http://www.strategy.bg/PublicConsultations/View.aspx?lang=bg-BG\&Id=4155 [Accessed 30.06.2019].

16. Ministerstvo na kulturata. (20196) Available from: http://mc.government.bg/ contestsc.php? $\mathrm{p}=163 \& \mathrm{~s}=164 \& \mathrm{c}=2100 \&$ CTypeID $=1 \& \mathrm{fbclid}=\mathrm{IwAR}$ OFCyLZSmIslmrOYS9d1Z x3pujsAKA-kjY_SGZ7--1QrCm_gcz3cyT9WTQ [Accessed 6.11.2019].

17. Mulcahy, K.V. (1995) The NEA and the Reauthorization Process: Congress and Arts Policy Issues. InBoulderAmerica's Commitment to Culture. Westview Press.

18. Mundy, S. (2010) Cultural policy: A short guide. Strasbourg: Council of Europe Publishing.

19. Natsionalen fond Kultura. (2019) Available from: http://programs.ncf.bg/web/files/ sessions/67/terms_document/mobility-iv-professionals.pdf [Accessed 25.10.2019].

20. Qiu, C. (2013). Issues in crowdfunding: Theoretical and empirical investigation on Kickstarter. Social Science Research Network.

21. Royal, C., \& Windsor, G. S. S. (2014). Microfinance, crowdfunding, and sustainability: A case study of telecenters in a South Asian developing country. Strategic Change, 23(7-8), pp.425438.

22. Saxton, G. D., \& Wang, L. (2014). The social network effect: The determinants of giving through social media. Nonprofit and Voluntary Sector Quarterly, 43(5), pp.850-868.

23. Throsby, D. (2001) Economics and culture. Cambridge University Press.

24. Throsby, D. (2011) The economics of cultural policy. Cambridge university press.

25. UNESCO. (2016) Culture, urban, future. Global report on culture for sustainable urban development. UNESCO: Paris.

26. UNESCO, (2018) Reshaping cultural policies: Advancing creativity for development. Global report, UNESCO: Paris. 